\title{
Prevalence of Musculo-skeletal Discomfort and Level of Functional Limitations among Physiotherapists in Karachi City
}

\section{DEEN Nazar*1, BADSHAH Munair ${ }^{2}$, SHAMIM Muhammad Omar ${ }^{3}$}

\author{
Editor: Constantin Munteanu, Romanian Association of Balneology, office@bioclima.ro
}

Reviewers: Dogaru Gabriela and Rotariu Mariana

*Corresponding author: DEEN Nazar, E-mail: din.nazar@yahoo.com

1. "Institute of Physical Therapy \& Rehabilitation, Jinnah Sindh Medical University, Karachi, Pakistan

2. "Islam College of Pharmacy", Pasrur Road Sialkot, Punjab Pakistan

3. "Department of Physiology, Islam Medical College", Pasrur Road Sialkot, Pakistan

\section{Abstract}

\section{Introduction:}

Musculoskeletal discomfort is one of the most prevalent muscular pain condition hindering normal activities reported by physical therapists and health care professionals generally engaged in handling and mobilizing patients. The study was conducted to find the prevalence of musculoskeletal discomfort and level of functional limitations in physiotherapists.

\section{Method:}

This research was questionnaire based cross sectional study conducted in Karachi city from January to April 2019.Data collection was completed from registered physical therapists employed in different institutions. Two questionnaires were filled by the physiotherapists. Questionnaire 01, including thirteen questions on functional activities of daily life which are potentially related to functional areas of Neck Disability Index (NDI). Questionnaire 02 was based on 1987 version of Nordic musculoskeletal questionnaire.

\section{Results:}

Participation of 80 physical therapists in the study.75\% was directly involved with patient handling and $25 \%$ were teachers. A total of $35 \%$ therapists reported 7 days symptoms prevalence with a higher prevalence in cervical (77.1\%), lower back (68.6\%) and upper back (51.4\%). Similarly 65\% workers showed previous 12 month symptoms with higher prevalence in neck (72.3\%). Gender prevalence of 7days and 12 months was high in female therapist.

\section{Conclusion:}

It has been concluded that 12 month prevalence of musculoskeletal discomfort was $65 \%$, whereas 7 days was $35 \%$ and level of functional limitation from activities was insignificant.

\section{Keywords: Epidemiology; musculoskeletal discomfort; Severity; Physical therapy,}

\section{INTRODUCTION}

National Institute for Occupational Safety and Health (NIOSH, 1997) in the USA describes musculoskeletal disorders as a condition which distresses any region of the body's musculoskeletal system encompassing skeleton, neurovascular bundles, tendons, ligaments, cartilage and discs as penalties from repetitive activities and job demands. ${ }^{1}$. The grounds of Musculoskeletal disorders in the workstation remain various and poorly understood. ${ }^{2}$ Musculo-skeletal symptoms with no fundamental pathology are both diagnostic and management dilemma for medical professions. Idiopathic musculoskeletal ache is probably to happen in $4.2 \%$ to $15.5 \%{ }^{3}$ Pain is the peak complains, its worldwide common origin is muscular disorder and is classified according to locality of pain. First is an upper limb complaint comprising any trauma or illness situated from lower cervical spine, shoulder up to fingers secondly is lower limb pain syndromes from hips to toes and the recorded one is low backache ${ }^{4}$. These disorders impact body's muscular system, bones and joints, tendons and ligaments, nervous system and grow over time, triggered either by the work itself and workstation. Health complications range from discomfort, minor pains and uneasiness to more thoughtful medical situations demanding time off work and even medical management. ${ }^{5}$ The working circumstances of male and female have been declared in certain studies which revealed high prevalence in female and they were less skilled with low pay and poorer controller of job stresses and advanced level of demands comparatively to male. ${ }^{6,7}$ The life time prevalence of work related musculoskeletal disorders (WRMDs) among physical therapists is $68 \%$ in the United Kingdom 55\% and 91\% in Australia, and $85 \%$ in Turkey. ${ }^{8}$ Another study showed the prevalence upto $64 \%$ and $93 \%{ }^{9}$. Even though prevalence rates of musculoskeletal disorders differ broadly depending on 
the body areas considered and the appliances applied for the assessment of signs and symptoms. Prevalence rates of more than $30 \%$ have been reported in several European epidemiological researches. ${ }^{\mathbf{1 0}}$ One wideranging study of WRMDs in physical therapists scrutinized their prevalence in nine different body areas. The peak twelve-monthly prevalence of WRMDs in physical therapists was in the low back (45\%), wrists and hands $(29.62 \%)$, upper back $(28.73 \%)$ and neck $(24.74 \%)$, Females were more suffering as compared to male from spinal and upper limb symptoms. ${ }^{11}$ Younger had the peak prevalence. ${ }^{12}$ Musculoskeletal disorders caused more serviceable restrictions in well-being states associated with disability and financial prudence in all regions of earth. ${ }^{13}$ Investigation uncovered the fact that job- linked musculoskeletal syndromes have a substantial influence on physical therapists with 1-6 physical therapists reported taking sick time, altering practice routines, shifting work surroundings or sendoff the occupation owing to WMSDs. ${ }^{14}$ Developing risk features for WMSDs is expected to drawn from care events like lifting, patients mobility with exercises, application of high level of force and adopting hazardous postures has been consistently connected with WRMDs and kinesiological analysis has confirmed very high associated musculoskeletal loads. ${ }^{15}$ Physical therapists consistently involved in manual therapy such as mobilization and manipulation and prone them to causative elements which linked to job ailments of both acute and chronic musculoskeletal illness. ${ }^{\mathbf{1 6}}$

The current study was designed in the same context to evaluate the burden of musculoskeletal discomfort and to initiate appropriate preventative plan.

\section{METHODOLOGY:}

This study was Cross-sectional research accomplished in City of Karachi, Pakistan from January to April 2019. Post research approval was obtained from the institutional Ethical Review Board, Islam Medical and Dental College, Sialkot. All registered physiotherapist working in public or private institutions, clinics, hospitals, self-employed and academic background in various specialties were conversant. The self-made questionnaire (01) was composed of socio-demographic, functional activities limitations questions closely related to neck pain and disability index (NDI) outcome measure while one question was about smoking habits and medication each. The questionnaire 02 implemented was standard version (1987) of Nordic Musculoskeletal Questionnaire, having questions related to different body areas including neck, shoulder, elbows, wrists, upper back, mid back, lower back, upper legs, knees, lower legs, and ankle joints with the descriptions of severity and frequency of symptoms, related work activities and the nature of discomfort and mode treatment taken to release pain. The questionnaires were filled by 100 registered physiotherapists to authorize and confirm their position and status with respect to the study measures. The Inclusion criterion was age range of 20-50 years, both sexes and registered practicing physiotherapists. Exclusion criteria included non-registered and nonworking physiotherapists, musculoskeletal and metabolic injuries and pregnant females. The participants were informed about the purpose and content of this research and written consent was taken. Total 100 proformas were distributed and 90 participants responds and return the forms. Out of 90 participants 10 were excluded due exclusion criteria and 80 were analyzed.

\section{RESULTS}

80 participants were interviewed $(51 \%$ were males and $49 \%$ females). $58 \%$ were in the age group of $20-30$ and $31 \%$ were in $30-40$ years. Majority (75\%) clinical therapists or hospital and 25\% were in academic setting. Duration of their working was assessed and it was found that $47 \%$ participated were working as physiotherapist for the last 1-3 years followed by $24 \%$ were working for the last 4-6 years. Majority (73\%) were working for a minimum of 8 hours whereas remaining was for 12 hours or more. The prevalence of 7 days' symptoms of jobrelated musculoskeletal disorders was found in $35 \%$, whereas 12 months prevalence was found in $65 \%$. In case of musculoskeletal discomfort, $36 \%$ participants were suffering with it for the last 7 days and $32 \%$ for $10-12$ months (Table 1 Section A).

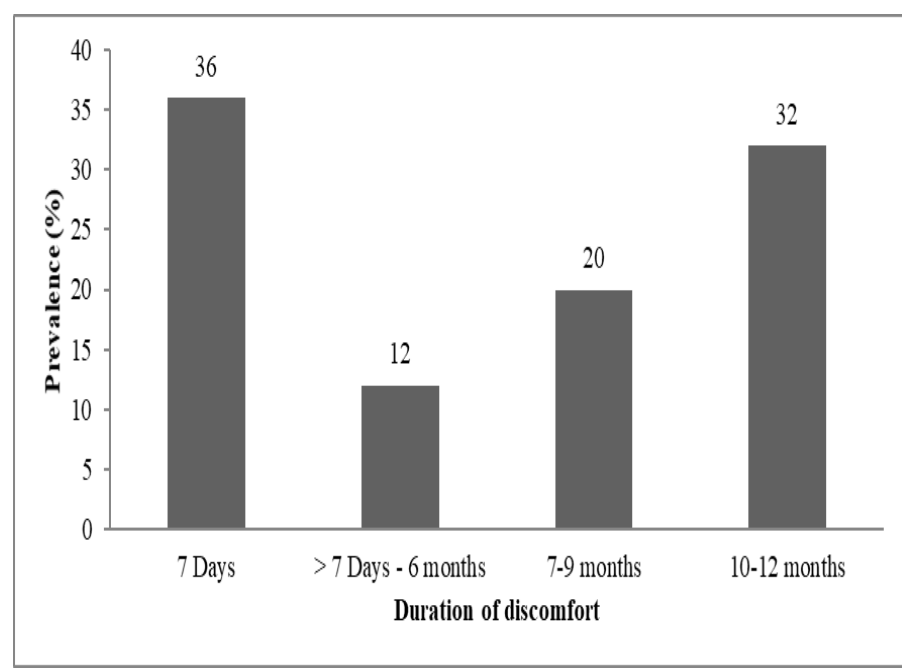

Figure 1. Distribution of duration of musculoskeletal discomfort

The prevalence of 7 days' symptoms of work-related musculoskeletal disorders was found in $35 \%$ which revealed that majority of the physiotherapists were suffering with neck pain $(77.1 \%)$, lower back $(68.6 \%)$ and upper back (51.4\%). The major remaining conditions were lower leg, mid back, knees, shoulder etc. Similar conditions were found in 12 months' prevalence, which was in $65 \%$ participants (Table 2 ). 
Table 1. Detailed characteristics of participants in the current study

\begin{tabular}{|c|c|c|c|}
\hline \multicolumn{2}{|c|}{ Demographic and job / Section A } & $\mathbf{N}$ & $\%$ \\
\hline \multirow{3}{*}{ Age (years) } & $20-30$ & 58 & 58.0 \\
\hline & $30-40$ & 31 & 31.0 \\
\hline & $40-50$ & 11 & 11.0 \\
\hline \multirow[b]{2}{*}{ Gender } & Male & 51 & 51.0 \\
\hline & Female & 49 & 49.0 \\
\hline \multirow{2}{*}{ Designation } & Academic & 25 & 25.0 \\
\hline & Clinical/Hospital/Home & 75 & 75.0 \\
\hline \multirow[t]{3}{*}{ Educational level } & Graduation & 43 & 43.0 \\
\hline & Master & 53 & 53.0 \\
\hline & $\mathrm{PhD}$ & 4 & 4.0 \\
\hline \multirow{3}{*}{ Working experience (Years) } & $1-5$ & 53 & 53.0 \\
\hline & $6-10$ & 34 & 34.0 \\
\hline & $>10$ & 13 & 13.0 \\
\hline \multirow{4}{*}{$\begin{array}{l}\text { Practicing duration as } \\
\text { Physiotherapist (Years) }\end{array}$} & $1-3$ & 47 & 47.0 \\
\hline & $4-6$ & 24 & 24.0 \\
\hline & $7-9$ & 18 & 18.0 \\
\hline & $>9$ & 11 & 11.0 \\
\hline \multirow{3}{*}{$\begin{array}{l}\text { Working hours per day } \\
\text { (hours) }\end{array}$} & 8 & 73 & 73.0 \\
\hline & 12 & 21 & 21.0 \\
\hline & $>12$ & 6 & 6.0 \\
\hline \multirow{2}{*}{ 7-days symptoms prevalence } & No & 65 & 65.0 \\
\hline & Yes & 35 & 35.0 \\
\hline \multirow{2}{*}{$\begin{array}{l}\text { 12-Months symptoms } \\
\text { prevalence }\end{array}$} & No & 35 & 35.0 \\
\hline & Yes & 65 & 65.0 \\
\hline \multirow{4}{*}{$\begin{array}{l}\text { Suffering from } \\
\text { musculoskeletal discomfort }\end{array}$} & 7 Days & 35 & 35.0 \\
\hline & $>7$ Days -6 months & 12 & 12.0 \\
\hline & $7-9$ months & 20 & 20.0 \\
\hline & $10-12$ months & 32 & 32.0 \\
\hline \multicolumn{4}{|c|}{ Musculoskeletal discomfort / Section B } \\
\hline & \begin{tabular}{|l|} 
Standing \\
\end{tabular} & 31 & 31.0 \\
\hline & Sitting & 37 & 37.0 \\
\hline & Bending & 20 & 20.0 \\
\hline yours musculoskeletal & Walking & 6 & 6.0 \\
\hline & Lying & 3 & 3.0 \\
\hline & Bending of knee & 2 & 2.0 \\
\hline & Static work & 1 & 1.0 \\
\hline & Standing & 10 & 10.0 \\
\hline & Sitting & 13 & 13.0 \\
\hline $\begin{array}{l}\text { Position which relleves your } \\
\text { musculoskeletal discomfort }\end{array}$ & Bending & 7 & 7.0 \\
\hline & Walking & 10 & 10.0 \\
\hline & Lying & 49 & 49.0 \\
\hline & Relax & 11 & 11.0 \\
\hline Prol & ems / Section C & & \\
\hline Does your musculoskeletal & $\begin{array}{r}\text { Yes } \\
\end{array}$ & 10 & 10.0 \\
\hline discomfort made you absent & No & 74 & 74.0 \\
\hline from work? & Often & 16 & 16.0 \\
\hline Does your musculoskeletal & Yes & 21 & 21.0 \\
\hline discomfort restrict you from & No & 60 & 60.0 \\
\hline Lifting? & Often & 19 & 19.0 \\
\hline Does your musculoskeletal & Yes & 16 & 16.0 \\
\hline discomfort make disturbance & No & 65 & 65.0 \\
\hline in your sleeping? & Often & 19 & 19.0 \\
\hline Does your musculoskeletal & Yes & 11 & 11.0 \\
\hline discomfort creating problem & No & 77 & 77.0 \\
\hline in managing personal care? & Often & 12 & 12.0 \\
\hline Does your musculoskeletal & Yes & 17 & 17.0 \\
\hline discomfort made you & No & 67 & 67.0 \\
\hline restricted from driving? & Often & 16 & 16.0 \\
\hline Does your musculoskeletal & Yes & 12 & 12.0 \\
\hline discomfort restrict you from & No & 68 & 68.0 \\
\hline recreational activities? & Often & 20 & 20.0 \\
\hline & Sedentary & 5 & 5.0 \\
\hline Describe your activity level & Active & 68 & 68.0 \\
\hline & Very Active & 27 & 27.0 \\
\hline Which of the following & Sitting & 28 & 28.0 \\
\hline describes your posture most & Standing & 57 & 57.0 \\
\hline of the time? & Walking & 15 & 15.0 \\
\hline What type of medication & Nil & 60 & 60.0 \\
\hline have you used & Analgesic & 40 & 40.0 \\
\hline
\end{tabular}

Table 2. Comparison of 7 days and 12 month symptoms prevalence along with 7-days and 12 months gender prevalence of musculoskeletal discomfort of body parts.

\begin{tabular}{|c|c|c|c|c|c|c|c|c|c|c|c|c|}
\hline \multirow{4}{*}{ Body Parts } & \multicolumn{12}{|c|}{ Prevalence } \\
\hline & \multirow{2}{*}{\multicolumn{2}{|c|}{$\begin{array}{c}\text { 7-days } \\
\text { symptoms } \\
\text { Prevalence }\end{array}$}} & \multirow{2}{*}{\multicolumn{2}{|c|}{$\begin{array}{l}\text { 12-Months } \\
\text { symptoms } \\
\text { Prevalence }\end{array}$}} & \multicolumn{4}{|c|}{7 days gender prevalence } & \multicolumn{4}{|c|}{12 month gender prevalence } \\
\hline & & & & & \multicolumn{2}{|c|}{ Male } & \multicolumn{2}{|c|}{ Female } & \multicolumn{2}{|c|}{ Male } & \multicolumn{2}{|c|}{ Female } \\
\hline & $\mathrm{N}$ & $\%$ & $\mathrm{~N}$ & $\%$ & $\mathrm{~N}$ & $\%$ & $\mathrm{~N}$ & $\%$ & $\mathrm{~N}$ & $\%$ & $\mathrm{~N}$ & $\%$ \\
\hline Neck & 27 & 77.1 & 47 & 72.3 & 10 & 76.9 & 17 & 77.3 & 27 & 71.1 & 20 & 74.1 \\
\hline Shoulder & 15 & 42.9 & 29 & 44.6 & 3 & 23.1 & 12 & 54.5 & 16 & 42.1 & 13 & 48.1 \\
\hline Elbows & 12 & 34.3 & 20 & 30.8 & 3 & 23.1 & 9 & 40.9 & 8 & 21.1 & 12 & 44.4 \\
\hline Wrists & 12 & 34.3 & 18 & 27.7 & 3 & 23.1 & 9 & 40.9 & 9 & 23.7 & 9 & 33.3 \\
\hline Hands & 13 & 37.1 & 17 & 26.2 & 3 & 23.1 & 10 & 45.5 & 8 & 21.1 & 9 & 33.3 \\
\hline Upper Back & 18 & 51.4 & 32 & 49.2 & 6 & 46.2 & 12 & 54.5 & 20 & 52.6 & 12 & 44.4 \\
\hline Mid Back & 15 & 42.9 & 23 & 35.4 & 4 & 30.8 & 11 & 50.0 & 15 & 39.5 & 8 & 29.6 \\
\hline Lower Back & 24 & 68.6 & 38 & 58.5 & 6 & 46.2 & 18 & 81.8 & 20 & 52.6 & 18 & 66.7 \\
\hline Upper Legs & 11 & 31.4 & 12 & 18.5 & 2 & 15.4 & 9 & 40.9 & 5 & 13.2 & 7 & 25.9 \\
\hline Lower Legs & 16 & 45.7 & 22 & 33.8 & 6 & 46.2 & 10 & 45.5 & 12 & 31.6 & 10 & 37.0 \\
\hline Knees & 15 & 42.9 & 21 & 32.3 & 2 & 15.4 & 13 & 59.1 & 7 & 18.4 & 14 & 51.9 \\
\hline Ankles & 11 & 31.4 & 17 & 26.2 & 2 & 15.4 & 9 & 40.9 & 10 & 26.3 & 7 & 25.9 \\
\hline
\end{tabular}

The same prevalence of 7 days' symptoms was assessed gender wise. It was found that the major symptom like neck pain was same in both male $(76.9 \%)$ and female $(77.3 \%)$.

The prevalence of 12 months' symptoms through gender difference revealed that neck related musculoskeletal disorder was the highest in both the groups. (Table 2).

The data was further analyzed for the frequency of musculoskeletal discomfort time period of the development of these symptoms in four time periods i.e., every day, 1-2 times per day, per month and per year as shown in Table 3.

Table 3. Frequency and Severity of 12-Months Prevalence of musculoskeletal discomfort symptoms by body parts.

\begin{tabular}{|c|c|c|c|c|c|c|c|c|c|c|c|c|c|c|c|c|}
\hline \multirow{3}{*}{ Body Parts } & \multicolumn{8}{|c|}{ Frequency } & \multicolumn{8}{|c|}{ Severity } \\
\hline & & 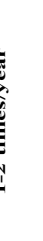 & & 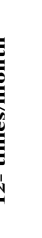 & & 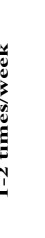 & & 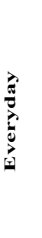 & & & & 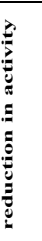 & & 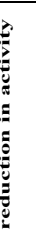 & 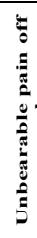 & \\
\hline & N & $\%$ & $\mathrm{~N}$ & $\%$ & $\mathrm{~N}$ & $\%$ & & $\%$ & $\mathrm{~N}$ & $\%$ & $\mathrm{~N}$ & $\%$ & $\mathrm{~N}$ & $\%$ & & $\%$ \\
\hline Neck & & 34 & 19 & 40.4 & 8 & 17 & 4 & 8.5 & 22 & 46.8 & 18 & 38.3 & 6 & 12.8 & 1 & 2.1 \\
\hline Shoulder & 14 & 48.3 & 8 & 27.6 & 4 & 13.8 & 3 & 10.3 & 16 & 55.2 & 10 & 34.5 & 1 & 3.4 & 2 & 6.9 \\
\hline Elbows & 14 & 70 & 5 & 25 & 1 & 5 & - & - & 18 & 90 & 2 & 10 & - & . & . & - \\
\hline Wrists & 15 & 83.3 & 3 & 16.7 & - & - & - & - & 16 & 88.9 & 2 & 11.1 & - & . & - & - \\
\hline Hands & 11 & 64.7 & 4 & 23.5 & 1 & 5.9 & 1 & 5.9 & 11 & 64.7 & 6 & 35.3 & - & . & - & - \\
\hline Upper Back & 11 & 34.4 & 15 & 46.9 & 5 & 15.6 & 1 & 3.1 & 15 & 46.9 & 10 & 31.2 & 6 & 18.8 & 1 & 3.1 \\
\hline Mid Back & & 39.1 & 9 & 39.1 & 3 & 13 & 2 & 8.7 & 15 & 65.2 & 5 & 21.7 & 3 & 13 & & \\
\hline Lower Back & 9 & 23.7 & 13 & 34.2 & 9 & 23.7 & 7 & 18.4 & 15 & 39.5 & 12 & 31.6 & 8 & 21.1 & 3 & 7.9 \\
\hline Upper Legs & 11 & 91.7 & 1 & 8.3 & . & . & - & - & 9 & 75 & 3 & 25 & - & . & - & $\cdot$ \\
\hline Lower Legs & 10 & 45.5 & 9 & 40.9 & 1 & 4.5 & 2 & 9.1 & 11 & 50 & 9 & 40.9 & 1 & 4.5 & 1 & 4.5 \\
\hline Knees & 7 & 33.3 & 7 & 33.3 & 1 & 4.8 & 6 & 28.6 & 10 & 47.6 & 9 & 42.9 & 1 & 4.8 & 1. & 4.8 \\
\hline Ankles & 11 & 64.7 & 4 & 23.5 & 2 & 11.8 & & . & 12 & 70.6 & 4 & 23.5 & 1 & 5.9 & & \\
\hline
\end{tabular}




\section{DISCUSSION}

The physical therapists working for hours are prone to develop musculoskeletal discomforts. To our knowledge interaction of muscular discomfort and activity limitation has not been addressed before. This study established the prevalence of musculoskeletal discomfort as a result of work correlated musculoskeletal complaints in physical therapists during the past 12 months was $65 \%$ and 7 days prevalence was $35 \%$ which is greater in comparison to previously reported statistics in different regions of the biosphere. ${ }^{17}$ The higher 12-month prevalence(occurrence) observed in this study can be illuminated by the circumstances under which physical therapists doing practice in Karachi City, particularly in public sector health center's organizations . For the reason that rehab units are short-staffed, such that a high quantifiable clinical workload is inescapable. Although the City government has tried attempts to ensure that all elementary hospital equipment is ergonomically suitable, other factors, such as increased patient-to-therapist ratios, low counted physical therapist staff, patient interaction time and therapists working in all specialties, might influence the higher incidence of WRMDs. Additionally, physical therapists were engaged with more than one patient simultaneously in some specialty areas, frequent home visits program and riding motor bikes import the high professional work-load makes them more vulnerable to musculoskeletal discomfort and injuries. ${ }^{18}$.The overall prevalence of musculoskeletal discomfort in all body regions was high in females. Neck pain $(77.3 \%)$ was most prominently noted in females while $76.9 \%$ in males. Accordingly, back pain was noted most prevalent in females and then in males. Our research findings were supported from international studies which suggest high musculoskeletal disorders in female due to physical weakness as compared to males, which showed $76 \%$ prevalence. ${ }^{19}$

In this study posture was one of the variable which aggravates musculoskeletal discomfort that sitting positions accounts $37 \%$ of the discomfort followed by standing posture $(31 \%)$ which probably shows static muscle work for a long period and aggravates muscular discomfort. The releasing position for all the muscular discomfort was lying position which probably showed no muscular activity. Our findings are consistent with the international study which concludes that physiotherapists working in pediatrics and musculoskeletal departments showed $67.7 \%$ musculoskeletal disorders due to static muscle work positions either sitting or standing. ${ }^{20}$

In this study, the 7 day prevalence showed that neck pain accounts $77 \%$, lower back pain $68.6 \%$ and upper back $51.4 \%$ and above calculations were found in $65 \%$ of our total sample size though intercontinental studies states that posterior lower spinal region was the utmost noted location for emerging job-related musculoskeletal disorders among physical therapists (51.7\%), persuaded by the cervical $(46.5 \%)$ and the dorsal spine region (44.8\%). The variations in these calculations may be due to the working environment, life style, ethnic values, socioeconomic status and daily working hours. ${ }^{21}$

In our study $60 \%$ of the physiotherapists were not restricted from lifting, $77 \%$ having no noticeable problems in self-care and also work off ratio was not significant because $74 \%$ were on duty despite of their musculoskeletal discomfort and $60 \%$ were not using any medications or physician help which showed consistency with the international study which concluded that physiotherapists took treatment from expert physiotherapists of different specialty, do not seek extra medical help and showed little limitation in their daily life. $^{22}$

\section{Conclusions}

There were 3 significant outcomes in our study:

1) 12-month occurrence of WMSDs among physical therapists in the City of Karachi was common; with the Neck pain affected most followed by lower back pain.

2) WMSDs were not associated to the member's demographics features.

3) Work responsibilities were not suffered by musculoskeletal ailments.

Conflict of interests: Declare none.

Funding: This study did not receive any grant.

Author contributions: All author contributed unfailingly

\section{References}

1. Hoe VC, Urquhart DM, Kelsall HL, Zamri EN, Sim MR. Ergonomic interventions for preventing work-related musculoskeletal disorders of the upper limb and neck among office workers. Cochrane Database of Systematic Reviews. 2018(10).

2. Muller S. A simple ergonomic intervention for neck and upper back musculoskeletal pain in computer users: Stellenbosch: Stellenbosch University; 2015.

3. Seidel DH, Ditchen DM, Hoehne-Hückstädt UM, Rieger MA, Steinhilber B. Quantitative measures of physical risk factors associated with work-related musculoskeletal disorders of the elbow: a systematic review. International journal of environmental research and public health. 2019;16(1):130.

4. Cullen KL, Irvin E, Collie A, Clay F, Gensby U, Jennings PA, Hogg-Johnson S, Kristman V, Laberge M, McKenzie D, Newnam S. Effectiveness of workplace interventions in return-to-work for musculoskeletal, pain-related and mental health conditions: an update of the evidence and messages for practitioners. Journal of Occupational Rehabilitation. 2018 Mar 1;28(1):1-5. 
5. Erick PN, Smith DR. Musculoskeletal disorders in the teaching profession: an emerging workplace hazard with significant repercussions for developing countries. Industrial health. 2015;53(4):385-6

6. Meeus M. Are pain beliefs, cognitions, and behaviors influenced by race, ethnicity, and culture in patients with chronic musculoskeletal pain: a systematic review. Pain Physician. 2018 Nov;21:541-58.

7. Alghwiri A, Marchetti G. Occupational back pain among schoolteachers in Jordan: estimated prevalence and factors associated with self-reported pain and work limitations. International Journal of Occupational Safety and Ergonomics. 2018;24(3):341-6.

8. Anyfantis I, Biska A. Musculoskeletal disorders among greek physiotherapists: traditional and emerging risk factors. Safety and Health at Work. 2018;9(3):314-8.

9. Hayes MJ, Smith DR, Taylor JA. Musculoskeletal disorders in a 3 year longitudinal cohort of dental hygiene students. American Dental Hygienists Association. 2014;88(1):36-41.

10. Tao YH, Wu YL, Huang WY. Factors influencing the occupational injuries of physical therapists in Taiwan: A hierarchical linear model approach. Work. 2017 Jan 1;58(3):299-307.

11. McPhail SM, Waite MC. Physical activity and healthrelated quality of life among physiotherapists: a cross sectional survey in an Australian hospital and health service. Journal of Occupational Medicine and Toxicology. 2014 Dec 1;9(1):1.

12. Alperovitch-Najenson D, Treger I, Kalichman L. Physical therapists versus nurses in a rehabilitation hospital: comparing prevalence of work-related musculoskeletal complaints and working conditions. Archives of Environmental and Occupational Health. 2014;69(1):33-9

13. Sebbag E, Felten R, Sagez F, Sibilia J, Devilliers H, Arnaud L. The world-wide burden of musculoskeletal diseases: a systematic analysis of the World Health Organization Burden of Diseases Database. Annals of the Rheumatic Diseases. 2019;1;78(6):844-8.

14. Milhem M, Kalichman L, Ezra D, Alperovitch-Najenson D. Work-related musculoskeletal disorders among physical therapists: A comprehensive narrative review. International Journal of Occupational Medicine and Environmental Health. 2016;29(5):735-47.

15. Richardson A, McNoe B, Derrett S, Harcombe H. Interventions to prevent and reduce the impact of musculoskeletal injuries among nurses: A systematic review. International Journal of Nursing Studies. 2018;82:58-67.

16. Kotejoshyer R, Punnett L, Dybel G, Buchholz B. Claim Costs, Musculoskeletal Health, and Work Exposure in Physical Therapists, Occupational Therapists, Physical Therapist Assistants, and Occupational Therapist Assistants: A Comparison Among Long-Term Care Jobs. Physical Therapy. 2019;99(2):183-93.

17. Vieira ER, Svoboda S, Belniak A, Brunt D, Rose-St Prix C, Roberts L, da Costa BR. Work-related musculoskeletal disorders among physical therapists: an online survey. Disability and rehabilitation. 2016 Mar 12;38(6):552-7.

18. Sundstrup E, Seeberg KGV, Bengtsen E, Andersen LL. A Systematic Review of Workplace Interventions to Rehabilitate Musculoskeletal Disorders Among Employees with Physical Demanding Work. Journal of Occupational Rehabilitation. 2020:1-25

19. Alghadir A, Zafar H, Iqbal ZA, Al-Eisa E. Work-related low back pain among physical therapists in Riyadh, Saudi Arabia. Workplace Health and Safety. 2017;65(8):337-45.

20. Alnaami I, Awadalla NJ, Alkhairy M, Alburidy S, Alqarni A, Algarni A, et al. Prevalence and factors associated with low back pain among health care workers in southwestern Saudi Arabia. BMC Musculoskeletal Disorders. 2019;20(1):56.

21. Alnaser MZ, Aljadi SH. Physical therapists with workrelated musculoskeletal disorders in the State of Kuwait: A comparison across countries and health care professions. Work. 2019;63(2):261-8.

22. Bae YH, Min KS. Associations between work-related musculoskeletal disorders, quality of life, and workplace stress in physical therapists. Industrial health. $2016 \mathrm{Jul}$ 31;54(4):347-53. 